Article

\title{
Jockey Career Length and Risk Factors for Loss from Thoroughbred Race Riding
}

\author{
Kylie Legg ${ }^{1, *(\mathbb{D})}$, Darryl Cochrane ${ }^{2}$, Erica Gee ${ }^{1}\left(\mathbb{C}\right.$ and Chris Rogers ${ }^{1,3}$ \\ 1 School of Veterinary Science, Massey University, Private Bag 11-222, Palmerston North 4442, New Zealand; \\ E.K.Gee@massey.ac.nz (E.G.); C.W.Rogers@massey.ac.nz (C.R.) \\ 2 School of Sport, Exercise and Nutrition, Massey University, Private Bag 11-222, Palmerston North 4442, \\ New Zealand; D.Cochrane@massey.ac.nz \\ 3 School of Agriculture and Environment, Massey University, Private Bag 11-222, Palmerston North 4442, \\ New Zealand \\ * Correspondence: k.legg@massey.ac.nz
}

Received: 24 August 2020; Accepted: 9 September 2020; Published: 10 September 2020

check for updates

\begin{abstract}
Professional thoroughbred racing jockeys repeatedly work close to physiological capacity during races, whilst maintaining low body weights, on a daily basis with no off-season. The effects of this on their career length is unknown. The aim of this study was to examine the career lengths and reasons for loss from the industry of 674 jockeys and apprentices who rode over 14 racing seasons and 421,596 race day starts in New Zealand. Descriptors were compared between jockeys in short (1-2 years), middle ( $3-9$ years) and long ( $>10$ years) career cohorts with descriptive statistics and Kaplan-Meier survival curves. The median career length for jockeys was 2 years (IQR 1-6). Long career cohort jockeys (11\%) had lower carried weights (IQR $56-57 \mathrm{~kg}, p=0.03$ ), 40 times the median number of rides per season (248, IQR 61-434, $p<0.001$ ), half the rate per 1000 rides of falling $(1.1,95 \%$ CI 1.0-1.2, $p=0.009)$ and 1.3 times the rate of winning $(100,95 \%$ CI 99-101, $p<0.01)$ than jockeys in the short career cohort. Jockeys who rode over 200 races per season had careers three times longer than jockeys with fewer races per season $(p<0.001)$. Half of the $40 \%$ of jockeys who failed to complete their apprenticeship were lost from the industry in their first year of race riding. In conclusion, most jockeys had short careers where the workload of a jockey and their ability to obtain rides had greater impact on career longevity than their performance.
\end{abstract}

Keywords: horse; thoroughbred racing; jockey; career; risk factors; equestrian athlete

\section{Introduction}

Thoroughbred racing is a major international sport in which jockey and horse work together, racing at speeds exceeding $60 \mathrm{~km} \mathrm{~h}^{-1}$ [1]. During races, the jockey is positioned over the withers of the horse in a crouched forward stance, in a state of continuous quasi-isometric movement-an activity that is extremely physically demanding [2,3]. Jockeys exercise close to their physiological capacity during a race $[2,3]$. At the same time, in order to meet the weight allocated to the horse to carry during a race, they must maintain a consistently low body mass year-round [1].

Professional jockeys may ride in flat or jumps races. Flat races are shorter than jumps races, occur year-round and comprise $96 \%$ of the total number of races in New Zealand, whereas jumps (hurdle and steeplechase) races occur only during the winter season and include up to 25 obstacles [4]. Races in New Zealand operate with minimum riding weights, facilitated by a handicapping system to enable equal competition, based on ratings assigned to each horse. Rating (flat, hurdles or steeples) is a dynamic measure of a horse's performance and is recalculated within two days of a horse's most recent race start. Higher rated (better performing) horses are assigned higher weights [5]. At present, 
minimum riding weights of $52 \mathrm{~kg}$ and $63 \mathrm{~kg}$ are in operation for flat and jumps jockeys, respectively, with the option for inexperienced (apprentice) jockeys to claim an allowance of 1-4 kgs depending on previous wins [5].

The workload of professional jockeys is high. In New Zealand, Australia and Ireland, jockeys ride in one to eight races a day, in two to four race days a week, with no off-season [6-8]. In the United Kingdom (UK) and the United States (USA) a jockeys' workload can be greater, with races occurring up to 7 days a week [1,9]. Jockeys have the added risk of falling from the horse, with incidence rates (per 1000 starts) of 1.2 for flat and 53-100 for jumps racing [10], increasing the potential for injury and confidence loss for jockeys. The effects of a consistently high workload, maintaining a low body mass year-round and the high potential for injury on potential career length of jockeys are unknown.

Although the careers of thoroughbred racehorses have been extensively studied [11-13], little is known about the career prospects of the jockeys that ride them. Retrospective questionnaires answered by current professional jockeys in USA, Korea, Ireland and Australia indicate that jockey career lengths are 10.9-15.9 years $[6,14,15]$, with a strongly skewed distribution toward the lower end of the scale $[8,9]$. However, these findings may be biased upwards because the studies only targeted jockeys who were found at the racetrack at the time of questioning. By default, this would include higher proportions of well-established jockeys who had secured a race day ride.

Whilst it is common for professional athletes in many sports to retire due to injury [16,17], in the sport of horse racing, jockeys leave their profession for a number of reasons, such as lack of rides, weight gain, injury, loss of confidence and competency $[8,9,18]$. Since little is currently known about the career length of jockeys in the thoroughbred industry, the aim of this study was to determine the career lengths and risk factors for loss from the industry of thoroughbred racing jockeys in New Zealand. This information would be beneficial in determining the costs and benefits to the jockey of riding more races, and to the industry in optimizing the selection and preparation of apprentices to fulfil the need for quality jockeys who can have long and successful careers. It was hypothesized that jockeys with longer careers would have more rides, fall less often and have more success than shorter career jockeys.

\section{Materials and Methods}

Data from all thoroughbred race-starts between 1 August 2005 and 17 April 2019 were supplied by New Zealand Thoroughbred Racing (NZTR), the governing body for thoroughbred racing in New Zealand. A racing season began on the 1 August and ended on the 31 July. Data were provided at the ride level and the following variables were extracted and used for further analysis: date of race; horse carried weight, assigned weight and domestic rating; jockey name, gender and age; race outcome (in the form of jockey falls or wins). Hurdle and steeplechase races were combined into one category of jumps races, to allow comparison between flat and jumps races.

For the purposes of this study, an apprentice was defined as a rider whose horses carried weight was $\leq 1 \mathrm{~kg}$ from the handicap weight assigned to the horse, whereas a jockey rode at the assigned horses' weight. Carried weight refers to the weight carried by the horse during the race. Three evenly populated workload cohorts of 'low', 'middle' and 'high' were created based on the number of rides each jockey rode per season. For flat and jumps racing respectively, those who rode 1-10 or 1-5 rides per season were assigned to the low cohort, jockeys who rode $10-200$ or $5-25$ rides per season were assigned to the middle cohort and jockeys who rode over 200 or 25 rides per season were assigned to the high cohort. Career length cohorts of 'short', 'middle' and 'long' were created based on the time between the first and last race ride of a jockey. Jockeys with careers of 1-2 (i.e., less than 3) years were assigned to the 'short' cohort, jockeys with careers of $\geq 3-9$ years were assigned to the 'middle' cohort and jockeys with careers of more than 10 years were assigned to the 'long' cohort. Analyses were conducted on flat racing jockeys only, except where jumps racing jockeys were used as a comparison group. Jockeys who were not licensed in New Zealand $(n=112)$ were removed from the data. 
The integrity of the data were checked using histograms, scatter plots and box plots, where outliers or points of interest were compared with the official NZTR database. Descriptive statistics were used to describe the data at population level for the career length cohorts. Counts and percentages were used to describe categorical data and median and interquartile range (IQR) were used to describe continuous data that were non-normally distributed. Incidence rates were calculated based on the number of falls or wins and number of rides during the time period and expressed as a rate per 1000 rides. Kaplan-Meier survival curves were used to estimate jockey career lengths, based on the dates of their appearances in the data set. Linear regression was used to calculate rates of survival probabilities. Seasonal trends were analyzed using seasonal and trend decomposition using loess (STL) plots and box plots. Normality was assessed using an Anderson-Darling test and Kruskal-Wallis tests for significance were used to compare differences between groups.

Analyses were conducted in RStudio (version 3.5.1, 2018; R Foundation for Statistical Computing, Vienna, Austria) with the level of significance set at $p<0.05$.

\section{Results}

During the period 1 August 2005-17 April 2019 there were 37,596 flat races over 4459 race days and 1528 jumps ( 897 hurdle and 631 steeple) races over 536 race days. There was a total of 421,596 ride opportunities, of which 407,948 were flat racing starters and 13,648 jumps racing starters.

Data were collected on 674 jockeys and apprentices licensed in New Zealand, the majority of which $(97 \%)$ rode in flat races and only $24 \%$ rode in a jumps race. Male jockeys accounted for $58 \%$ of the total number of registered jockeys or apprentices over the study period. The distribution of career length was highly positively skewed (Figure 1). The median career length of all jockeys was two (IQR 1-6) seasons, with no differences in rate of loss of jockeys between race type (flat or jumps $p=0.5$ ). After the first year, the rate of loss of female jockeys was higher than for male jockeys $(p=0.006)$. Jockeys who began their careers under 18 years of age were twice as likely to remain in their career than jockeys who began at an older age ( $p=0.02)$. Twenty-four $(4 \%)$ jockeys rode for all 14 race seasons.

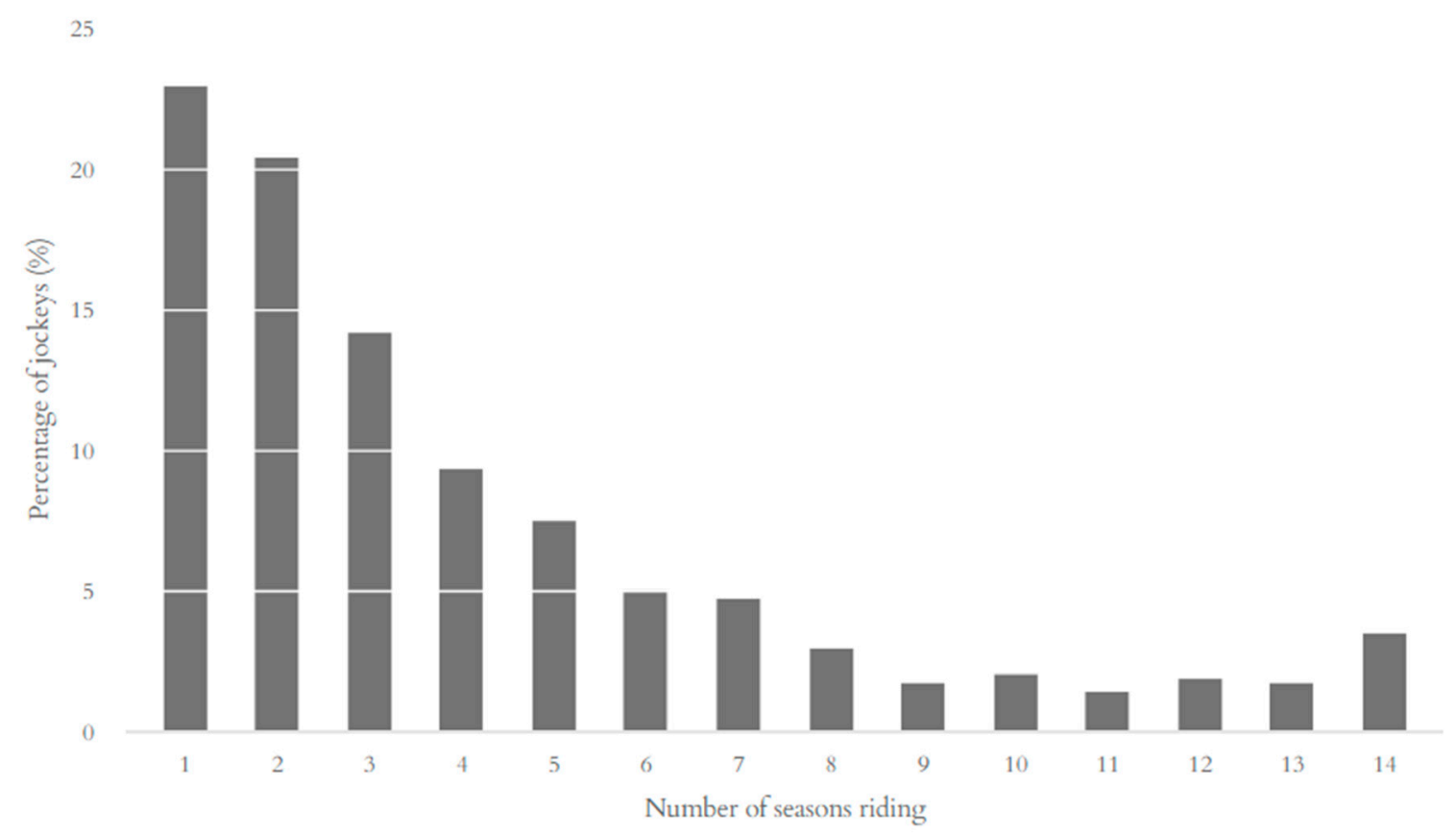

Figure 1. Number of seasons riding for flat and jumps racing jockeys for the 2005/6-2018/9 racing seasons.

Jockeys in the long career length cohort (11\%) were more likely to be male and had more rides and wins per season than jockeys in the short (43\%) and middle (46\%) career length cohorts (Table 1). 
Jockeys in the short career cohort had twice the incidence rate of falls and were less likely to ride a winner than jockeys in the high career length cohort.

Table 1. Characteristics of flat racing jockeys with short (1-2 years), middle (3-9 years) and long (>10 years) career lengths for the 2005/6-2018/9 racing seasons.

\begin{tabular}{|c|c|c|c|c|c|c|c|}
\hline \multirow[t]{2}{*}{ Descriptor } & \multicolumn{2}{|c|}{ Short } & \multicolumn{2}{|c|}{ Middle } & \multicolumn{2}{|c|}{ Long } & \multirow[t]{2}{*}{$p$ Value } \\
\hline & \multicolumn{6}{|c|}{ Number of observations (\%) } & \\
\hline Female & 120 & $42 \%$ & 133 & $44 \%$ & 16 & $23 \%$ & \\
\hline \multirow[t]{2}{*}{ Male } & 152 & $54 \%$ & 168 & $55 \%$ & 54 & $77 \%$ & 0.001 \\
\hline & \multicolumn{6}{|c|}{ Median (IQR) } & \\
\hline Age at first appearance (yrs) & 25 & $(22-31)$ & 23 & $(20-27)$ & 25 & $(21-31)$ & $<0.001$ \\
\hline Average carried weight (kg) & 56 & $(54-67)$ & 56 & $(54-64)$ & 56 & $(56-57)$ & 0.03 \\
\hline Average flat rating & 61 & $(57-65)$ & 61 & $(59-63)$ & 62 & $(61-64)$ & 0.03 \\
\hline Rides per season & 6 & $(2-18)$ & 44 & $(10-136)$ & 248 & $(61-434)$ & $<0.001$ \\
\hline Wins per season & 0 & $(0-1)$ & 2 & $(1-11)$ & 18 & $(4-43)$ & $<0.001$ \\
\hline Total number of falls & 0 & $(0-0)$ & 0 & $(0-1)$ & 3 & $(1-5)$ & $<0.001$ \\
\hline \multirow[t]{2}{*}{ Total number of wins } & 0 & $(0-2)$ & 10 & $(2-50)$ & 221 & $(50-558)$ & $<0.001$ \\
\hline & \multicolumn{6}{|c|}{ Incidence Rate (95\% CI) } & \\
\hline Falls/1000 rides & 1.9 & $1.3-2.8$ & 1.3 & $1.1-1.5$ & 1.1 & $1.0-1.2$ & 0.009 \\
\hline Wins/1000 rides & 75 & $71-80$ & 84 & $83-86$ & 100 & 99-101 & $<0.001$ \\
\hline
\end{tabular}

The total number of falls and wins experienced by a jockey increased with career length. There was no difference between the median time (456 days, IQR 174-880) and number of rides (239, IQR 66-508) from the beginning of a flat racing jockey's career to their first race-day fall and the time (715 days, IQR $277-1460, p=0.6)$ and number of rides (226, IQR 62-738, $p=0.6)$ from their last race-day fall until the end of their career for flat racing jockeys from all cohorts. There was a non-significant trend for both time and number of rides before $(p=0.5)$ and after $(p=0.7)$ first and last race-day fall to be greater for longer career lengths.

The median career length of flat racing jockeys who had more than one fall over their career $(n=58)$ was more than 14 years, with a low linear rate of loss $\left(4 \%\right.$ per season, $\left.R^{2}=0.9\right)$. This was longer than the median career length of jockeys with one fall ( 5 years, $n=92)$ or no falls (1.5 years, $n=507$, $p<0.001$.

Similar to falls, the total number of wins by a jockey increased with career length. There was no difference between the median time (44 days, IQR 8-214) and number of rides (eight, IQR 3-18) from the beginning of a flat racing jockey's career to their first race-day win and the time (42 days, IQR $7-280, p=0.1)$ and number of rides (10, IQR 4-19, $p=0.3)$ from their last race-day win until the end of their career for flat racing jockeys from all cohorts $(p>0.05)$. There were no differences between career length cohorts from time until first win, and from last win until end of careers.

Career length and rate of loss from the industry was strongly associated with the number of rides ridden by a flat racing jockey during a season (Figure 2). Approximately four (5\%) high workload cohort jockeys $(n=78)$ left the sport each season resulting in a median career of 10 seasons, over threefold longer than observed for jockeys from low and middle workload cohorts (two to three seasons). This was similar for jumps racing, where high workload cohort jockeys $(n=26)$ had median careers of 6 years and approximately two jockeys (8\%) leaving each season, twice as long as those in the middle workload cohort $(n=56)$, and three times as long as jockeys in the low workload cohort $(\mathrm{n}=77, p<0.001)$, both with exponential rates of loss. 


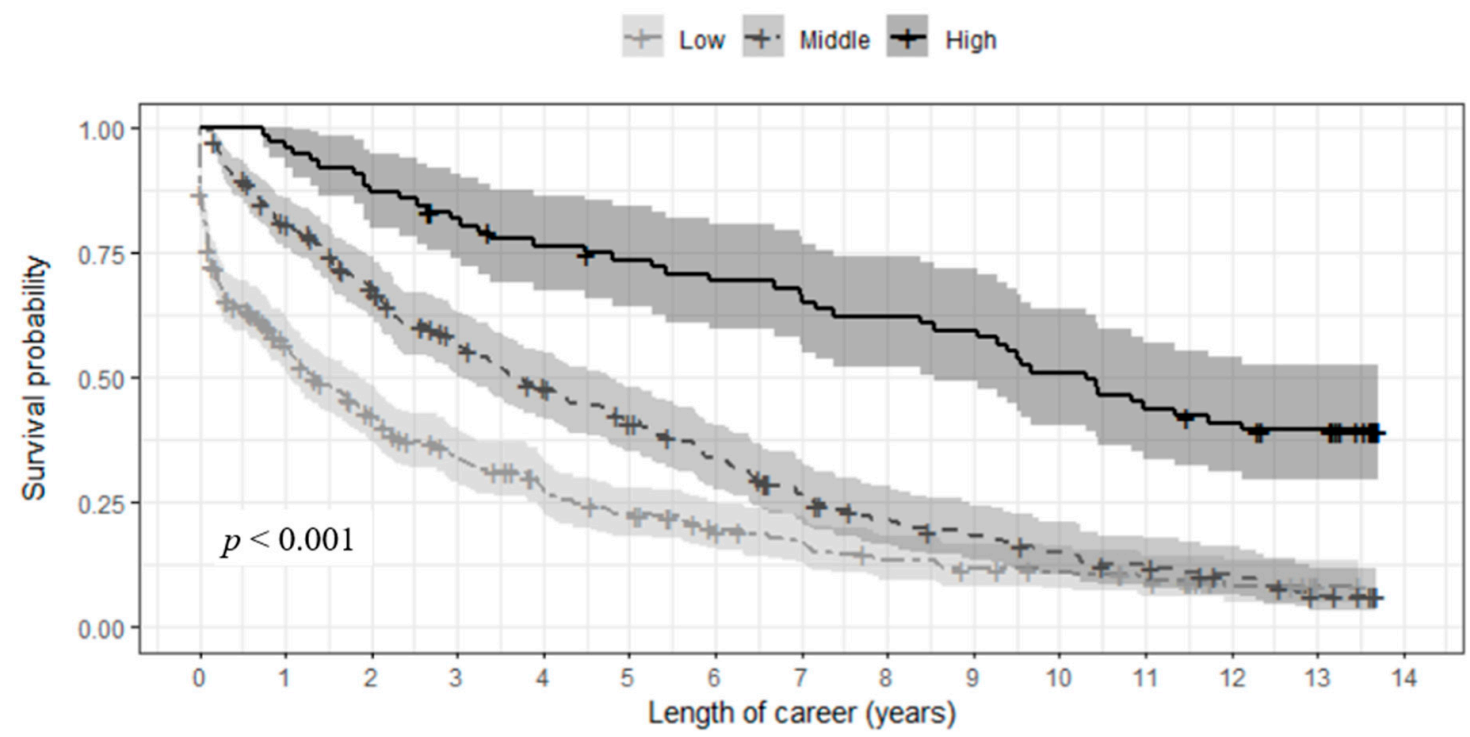

Figure 2. Length of career of flat racing jockeys who first appear in low (1-10 rides/season, $n=335$ ), middle (10-200 rides, $\mathrm{n}=244$ ) or high (>200 rides, $\mathrm{n}=78$ ) workload cohorts for the 2005/6-2018/9 racing seasons. Shaded area indicates $95 \%$ confidence interval.

\subsection{Apprentices}

There was a difference in career length for those jockeys who completed their apprenticeship and those who did not (Figure 3). Only 40\% (131/331) of apprentices completed their apprenticeship training. Half of the jockeys who did not complete their apprenticeship during the time period were lost within a year of their first race day ride. For those who did complete their apprenticeship, their median career length was 6.5 years. For the $32 \%$ of jockeys who continued to ride for more than 7 years, the linear rate of loss slowed by half $\left(8 \%\right.$ to $3 \%$ per year, $\left.R^{2}=0.97\right)$.

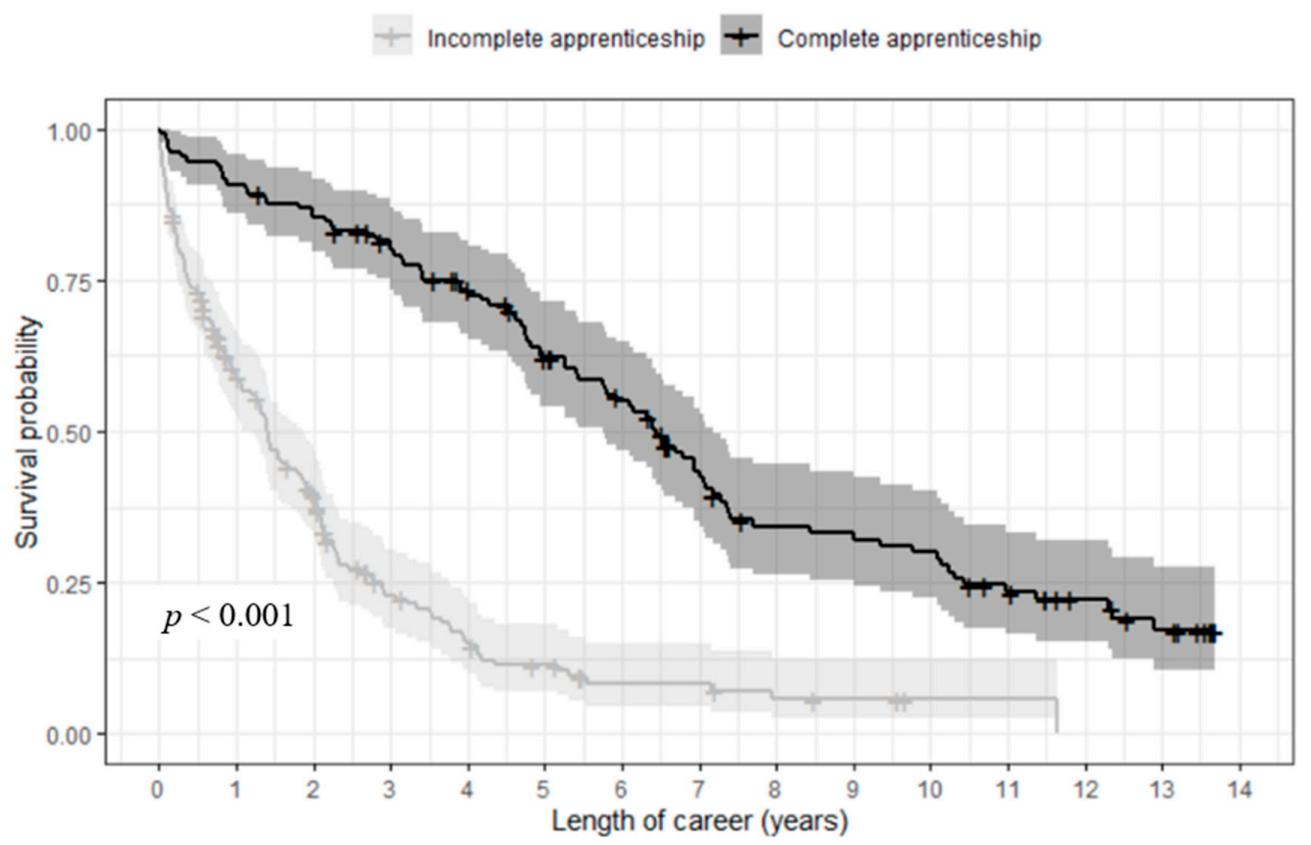

Figure 3. Career survival probability for apprentices that completed their apprenticeship $(\mathrm{n}=131)$ and those that did not $(n=200)$ for the 2005/6-2018/9 racing seasons. Shaded area denotes $95 \%$ confidence interval. 


\subsection{Yearly Racing}

Race opportunities were available year-round, but there were more horses flat racing in the summer (October-January) than in winter months (June-September) (Figure 4). The rides of jockeys in the high workload cohort followed this seasonal trend, with two seasonal peaks in ride numbers in December (summer) and April (autumn), respectively, of 1.7 times and 1.5 times the month with the least number of rides in August (winter). Apprentices also had two seasonal peaks in ride numbers in December and May of 1.5 and 1.7 times that of the number of rides in February, the month in which they had the least number of rides. Jockeys in the middle workload cohort had two seasonal peaks in ride numbers in May-July and November-January of 2.2 and 1.5 times the number of rides in February, when they had least rides. Jockeys in the low workload cohort had only one seasonal peak in ride numbers, riding twice as many races from November-January than in April-July.

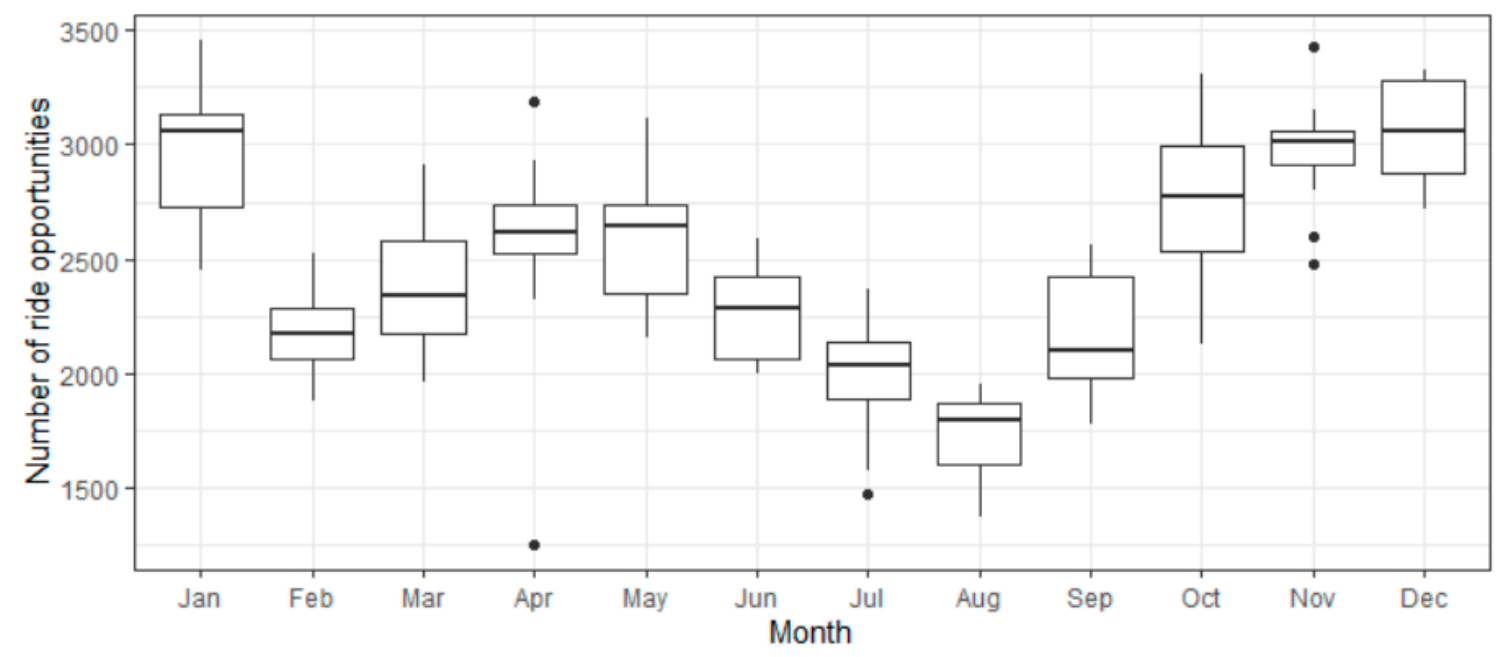

Figure 4. Number of monthly flat racing ride opportunities for the 2005/6-2018/9 racing seasons.

Apprentices rode in a higher proportion of races during the winter months than the summer months. Jockeys from the high workload cohort rode the majority of two-year-old races year-round compared with apprentices or jockeys in the low and middle workload cohorts.

\section{Discussion}

This study provides new information documenting the career lengths and reasons for loss from the industry for thoroughbred racing jockeys in New Zealand. The career length of the majority of jockeys in New Zealand was short ( $<3$ years), and similar for both flat and jumps racing jockeys. A higher workload (in terms of number of races ridden) was positively associated with the career length of jockeys in New Zealand. Similar findings have been previously reported in qualitative studies in Australia and UK, where lack of rides was reported to be the major limiting factor for most jockey's careers $[8,18]$. This indicates there is a surplus number of jockeys than is required by the available ride opportunities.

Jockeys who had high workloads in the current study had similar career lengths to jockeys in USA, Korea and Australia of 10-15 years $[8,9,14,15]$. The data set used in the current study was a cross section of 14 seasons, that may erroneously group jockeys at the start and end of their careers into lower career cohorts and does not record the length of careers which span for more than 14 seasons. This effect was considered minimal, due to the consistency of the trends over the data set and similarity of career lengths with jockeys from other jurisdictions. Though there were relatively even numbers of male and female jockeys entering the industry, the rate of loss of female jockeys was higher, indicating that longer career jockeys were more likely to be male. 


\subsection{Long Career Cohort Jockeys}

Jockeys with longer careers were less likely to fall during a race and more likely to ride a winner than jockeys with shorter careers, indicating that they ride more safely and more successfully than their counterparts. However, those with longer careers had a higher total number of falls and the rate of loss of jockeys with more than two falls over the length of their career was low. This indicates that falling (and the cumulative frequency thereof) may not be a driver of career longevity and performance for flat racing jockeys. In addition, the lack of association between time or number of rides until the first fall or win of a jockey and between their last fall or win and the end of their career indicates that neither falling nor winning was a driving factor for career length. Thus, the higher number of falls by longer career jockeys may be a simple reflection of the greater time spent at risk. The higher total number of wins by longer career jockeys would increase their status and enable them to more easily obtain future rides, thereby prolonging their career. This view was supported by the observation that longer career jockeys rode horses with higher ratings indicating that they were able to attain higher quality rides with more chance of success.

Although longer career jockeys fell less often than shorter career jockeys, as a group they had more falls. Injury has previously been identified as one of the factors for jockeys ending their careers $[8,18]$. For example, Korean flat racing jockeys with an average career span of 11.6 years reported at least one injury, most occurring during practice or competition and due to difficulties in handling horses, though it was unclear if this was whilst riding or ground handling horses [14]. In the UK, half of the accidents reported in racehorse stables were from falling from a horse during training [19]. Although falls occurring pre- and post-race, or during trackwork and training were not taken into account in the present study, falls occurring during a race are more likely to result in injury to the jockey $[20,21]$ and account for approximately half of jockey race day falls in New Zealand [22]. In addition, despite having fewer racing opportunities, jumps racing jockeys fall during the race 50-100 times more often than flat racing jockeys (or once every 10-20 races) [10]. Thus, falling from a horse is a major risk, not only during a competitive race, but also during training activities. For these reasons, training on how to fall safely early in a jockey's career may help to reduce the risk of injury from falling from a horse.

In the current study, long career cohort jockeys rode at a smaller range of carried weights compared to short and middle career length cohorts. The year-round ride opportunities require jockeys to be able to meet these riding weights consistently, and inability to meet the weight requirements has been identified as limiting jockey careers in Australia and USA [8,18]. Therefore, the ability to make weight may be an important driver for racing success.

Jockeys have been found to be smaller, lighter, have better balance and reaction times, greater anaerobic and aerobic fitness and greater muscular strength and power than track riders who exercise racehorses daily [23]. Therefore, factors such as jockey phenotype, fitness, or work ethic (mental stamina) may be more important predictors of jockey success/longevity than racing performance. These factors may be apparent early on in a jockey's career, as shown by the high rate of loss of non-graduating apprentices after just 6 months. This may underline the importance of a pre-selection criteria early in a jockey's career, as occurs in other sports [17], to identify candidates who are most likely to be successful as jockeys. Thus, future studies should investigate the optimal physical characteristics of jockeys in order to maximize 'talent' potential.

\subsection{Apprentices}

The current results revealed that jockey apprenticeship programs had a high rate of loss (40\%), half of which was within a year of their first race day ride. This was lower than observed in UK, with the director of the British racing school in 2000 estimating that nine out of 10 apprentices failed to become full professional jockeys [18]. In the present study, the median combined (apprenticeship and jockey) career length of graduating apprentices of 6-7 years indicated that additional investment into early careers of jockey may be beneficial to increase workforce retention. This has been shown to be effective; a structured training program was introduced to apprentices in Victoria, Australia in 1992 
and reduced the numbers of the annual apprentice intake that failed to become jockeys from $25 \%$ to $10 \%$ [8]. Therefore, appropriate industry changes can improve jockey retention and possibly career length in the industry. Having rigorous selection criteria and decreasing the apprentice intake may allow more intensive investment into the training and education of new apprentices. In association with a specialized apprentice training program, these measures may help to retain and support jockeys in their career.

\subsection{Seasonal Rides}

The current analysis revealed a seasonal trend in ride opportunities for jockeys, with more rides during spring carnival racing, and in autumn, where there is a cross over with 'winter' horses commencing work, and 'summer' horses finishing their season.

High workload cohort jockeys had their highest number of races during spring and summer racing, when most of the high stakes races occur, and 2-year-olds are introduced to racing. Proportionally more licensed and high workload cohort jockeys rode in 2-year-old races, indicating that a new and inexperienced horse with unknown potential was given the best possible chance of winning by having a more experienced rider. The summer peak in ride numbers by low workload jockeys may reflect the extra rides they are able to acquire due to the higher number of ride opportunities in summer. Interestingly, the peak for the middle workload cohort jockeys and apprentices was highest in autumn, indicating that these jockeys may ride more of the (slower) 'winter' racing horses, or experienced horses at the end of the summer racing season. As inexperienced jockeys and inexperienced horses have both been found to be risk factors in jockey falls [10,24-26], this is an interesting finding which indicated the industry is actively protecting the interests of the less experienced jockeys, giving them valuable race experience in potentially slower races.

The large numbers of jockeys competing for a fixed number of ride opportunities results in high selectivity for the high performing jockeys. It has been identified that riding a race is more physically demanding than riding daily trackwork [27] and jockeys rarely participate in additional off-horse physical training regimes except as a measure to reduce weight $[6,7]$. The short career length of the majority of jockeys indicate that they may not be physically or mentally prepared or able to meet the demands of riding in a race, thus not able to either meet the weight requirements, or perform successfully. Reducing the numbers of licensed jockeys may help to extend future jockeys' careers by ensuring there were sufficient riding opportunities. Better selection of and support for candidates who are able to join the high workload jockey cohort would reduce risk to both horse and rider and loss of athletes from the sport.

\section{Conclusions}

The majority of jockeys in New Zealand over the 2005/6-2018/9 racing seasons had short careers of two years, whilst jockeys who rode in more races had longer careers. The $11 \%$ of jockeys with careers of greater than 10 years rode at consistently low weights, had a lower fall incidence rate, and were more likely to win races than jockeys with shorter careers. In determining jockey career lengths, the ability to obtain rides (and to make riding weights) was more important than falling or winning. There was a high rate of loss of apprentices, the majority of them leaving one year after their first race day ride, highlighting the importance of developing appropriate selection criteria for jockeys.

Author Contributions: Conceptualization, K.L. and C.R.; methodology, K.L. and C.R.; formal analysis, K.L.; writing—original draft preparation, K.L.; writing—review and editing, K.L., D.C., E.G., C.R.; supervision, D.C., E.G., C.R.; funding acquisition, C.R. All authors have read and agreed to the published version of the manuscript.

Funding: This project was funded in part from the New Zealand Equine Trust grant ET 2/2019, ET 9/2017 \& ET 1/2016.

Acknowledgments: The authors would like to thank New Zealand Thoroughbred Racing for provision of the data. 
Conflicts of Interest: The authors declare no conflict of interest. The funders had no role in the design of the study; in the collection, analyses, or interpretation of data; in the writing of the manuscript, or in the decision to publish the results.

\section{References}

1. Warrington, G.; Dolan, E.; McGoldrick, A.; McEvoy, J.; MacManus, C.; Griffin, M.; Lyons, D. Chronic weight control impacts on physiological function and bone health in elite jockeys. J. Sports Sci. 2009, 27, 543-550. [CrossRef] [PubMed]

2. Cullen, S.J.; O'Loughlin, G.; McGoldrick, A.; Smyth, B.; May, G.; Warrington, G. Physiological demands of flat horse racing jockeys. J. Strength Cond. Res. 2015, 29, 3060-3066. [CrossRef]

3. Trowbridge, E.A.; Cotterill, J.V.; Crofts, C.E. The physical demands of riding in National Hunt races. Eur. J. Appl. Physiol. 1995, 70, 66-69. [CrossRef] [PubMed]

4. Bolwell, C.F.; Rogers, C.W.; Gee, E.K.; Rosanowski, S.M. Descriptive statistics and the pattern of horse racing in New Zealand. 1. Thoroughbred racing. Anim. Prod. Sci. 2016, 56, 77-81. [CrossRef]

5. New Zealand Thoroughbred Racing. Handicapping Guide; New Zealand Thoroughbred Racing Inc.: Wellington, New Zealand, 2019.

6. Dolan, E.; O'Connor, H.; McGoldrick, A.; O’Loughlin, G.; Lyons, D.; Warrington, G. Nutritional, lifestyle, and weight control practices of professional jockeys. J. Sports Sci. 2011, 29, 791-799. [CrossRef] [PubMed]

7. Leydon, M.A.; Wall, C. New Zealand jockeys' dietary habits and their potential impact on health. Int. J. Sport Nutr. Exerc. Metab. 2002, 12, 220-237. [CrossRef]

8. Speed, H.; Seedsman, T.; Morris, T.; Sullivan, R. The Welfare of Retired Jockeys; Victoria University of Technology, Centre for Rehabilitation, Exercise and Sports Science: Melbourne, Australia, 2001.

9. Press, J.M.; Davis, P.D.; Wiesner, S.L.; Heinemann, A.; Semik, P.; Addison, R.G. The national jockey injury study: An analysis of injuries to professional horse-racing jockeys. Clin. J. Sport Med. 1995, 5, $236-240$. [CrossRef]

10. Legg, K.A.; Cochrane, D.J.; Bolwell, C.F.; Gee, E.K.; Rogers, C.W. Incidence and risk factors for race-day jockey falls over fourteen years. J. Sci. Med. Sport 2020, in press. [CrossRef]

11. Tanner, J.C.; Rogers, C.W.; Firth, E.C. The association of 2-year-old training milestones with career length and racing success in a sample of Thoroughbred horses in New Zealand. Equine Vet. J. 2013, 45, 20-24. [CrossRef]

12. Sobczyńska, M. The effect of selected factors on length of racing career in Thoroughbred racehorses in Poland. Anim. Sci. Pap. Rep. 2007, 25, 131-141.

13. Jeffcott, L.B.; Rossdale, P.D.; Freestone, J.; Frank, C.J.; Towers-Clark, P.F. An assessment of wastage in Thoroughbred racing from conception to 4 years of age. Equine Vet. J. 1982, 14, 185-198. [CrossRef] [PubMed]

14. Jeon, S.; Cho, K.; Ok, G.; Lee, S.; Park, H. Weight loss practice, nutritional status, bone health, and injury history: A profile of professional jockeys in Korea. J. Exerc. Nutr. Biochem. 2018, 22, 27-34. [CrossRef] [PubMed]

15. Kiely, M.; Warrington, G.; McGoldrick, A.; Cullen, S.J. Physical preparation strategies of professional jockeys. J. Strength Cond. Res. 2020, in press. [CrossRef]

16. Witnauer, W.D.; Rogers, R.G.; Saint Onge, J.M. Major league baseball career length in the twentieth century. Pop. Res. Policy Rev. 2007, 26, 371-386. [CrossRef] [PubMed]

17. Baker, J.; Koz, D.; Kungl, A.-M.; Fraser-Thomas, J.; Schorer, J. Staying at the top: Playing position and performance affect career length in professional sport. High. Abil. Stud. 2013, 24, 63-76. [CrossRef]

18. Vamplew, W. Still crazy after all those years: Continuity in a changing labour market for professional jockeys. Sport Soc. 2016, 19, 378-399. [CrossRef]

19. Filby, M.; Jackson, C.; Turner, M. Only falls and horses: Accidents and injuries in racehorse training. Occup. Med. 2012, 62, 343-349. [CrossRef]

20. Waller, A.E.; Daniels, J.L.; Weaver, N.L.; Robinson, P. Jockey injuries in the United States. Am. J. Emerg. Med. 2001, 283, 1326-1328. [CrossRef]

21. Curry, B.A.; Hitchens, P.L.; Otahal, P.; Si, L.; Palmer, A.J. Australian insurance costs of jockeys injured in a race-day fall. Occup. Med. 2016, 66, 222-229. [CrossRef]

22. Bolwell, C.F.; Rogers, C.W.; Gee, E.K. Descriptive epidemiology of race-day jockey falls and injuries in New Zealand. Comp. Exerc. Physiol. 2014, 10, 49-55. [CrossRef] 
23. Hitchens, P.; Blizzard, L.; Jones, G.; Day, L.; Fell, J. Are physiological attributes of jockeys predictors of falls? A pilot study. Br. Med. J. Open 2011, 1, e000142. [CrossRef] [PubMed]

24. Hitchens, P.; Blizzard, L.; Jones, G.; Day, L.; Fell, J. Predictors of race-day jockey falls in jumps racing in Australia. Accid. Anal. Prev. 2011, 43, 840-847. [CrossRef] [PubMed]

25. Hitchens, P.L.; Blizzard, C.L.; Jones, G.; Day, L.; Fell, J. Predictors of race-day jockey falls in flat racing in Australia. Occup. Environ. Med. 2010, 67, 693-698. [CrossRef] [PubMed]

26. O'Connor, S.; Warrington, G.; Mb, A.M.; Cullen, S. A 9-year epidemiologic study (2007-2015) on race-day jockey fall and injury incidence in amateur irish horse racing. J. Athl. Train. 2018, 53, 950-955. [CrossRef] [PubMed]

27. Kiely, M.A.; Warrington, G.D.; McGoldrick, A.; O'Loughlin, G.; Cullen, S. Physiological demands of daily riding gaits in jockeys. J. Sports Med. Phys. Fit. 2019, 59, 394-398. [CrossRef]

(C) 2020 by the authors. Licensee MDPI, Basel, Switzerland. This article is an open access article distributed under the terms and conditions of the Creative Commons Attribution (CC BY) license (http://creativecommons.org/licenses/by/4.0/). 